Gut, 1980, 21, 63-71

\title{
Distribution of basement membrane proteins in normal and fibrotic human liver: collagen type IV, laminin, and fibronectin
}

\author{
E HAHN ${ }^{1}$, G WICK, D PENCEV, AND R TIMPL \\ From the Department of Medicine, University of Marburg/Lahn, FRG, Department of General and \\ Experimental Pathology, University of Innsbruck, Austria, and Max-Planck-Institut für Biochemie, \\ Martinsried, FRG
}

SUMMARY Specific antibodies to collagen type IV, laminin, and fibronectin were used to localise these proteins by indirect immunofluorescence in frozen sections of normal and fibrotic liver. In normal livers distinct staining was found in basement membranes of blood and lymph vessels, of bile ducts and ductules and around nerve axons. Positive reactions for type IV collagen and fibronectin were also observed in the perisinusoidal space, while hepatocytes and most of the interstitial matrix of portal fields remained unstained. Liver specimens obtained from patients with alcoholic liver disease (fatty liver, hepatitis or cirrhosis) and chronic active hepatitis showed a more intense reaction with the antibodies in the perisinusoidal space including now distinct staining for laminin. These patterns were particularly prominent at borders between fibrotic septa and remnants of parenchyma or pseudolobules. Strong reactions were also found for type IV collagen and fibronectin in the periportal interstitium and in large fibrotic areas. The findings support previous electronmicroscopical and chemical evidence for increased basement membrane production in human liver fibrosis and demonstrate that this may involve different proteins and occur at different anatomical sites.

Basement membranes are extracellular matrices composed of collagen type IV and non-collagenous proteins (Kefalides, 1973). Electron microscopy visualises these membranes as amorphous, laminar structures in the proximity of various cell types (epithelial, muscle, or nerve cells) separating these cells from underlying or surrounding connective tissue (Vracko, 1974). In human liver, basement membranes are found in blood and lymphatic vessels and around bile ducts. Their presence in the lobular regions particularly between sinusoidal lining cells and hepatocytes is still controversial (Schaffner and Popper, 1963; Vracko, 1974). Lack of typical basement membrane structures in the perisinusoidal space in normal liver is considered to allow an intimate contact between blood and parenchymal cells. The appearance of a continuous perisinusoidal basement membrane in experimental liver injury (Bucher, 1963; Cossel, 1966) and in human liver fibrosis (Schaffner and Popper, 1963;

1Address for correspondence and reprint requests: Max-PlanckInstitut für Biochemie Am Klopferspitz D-8033 Martinsried.

Received for publication 4 September 1979
Phillips and Steiner, 1966; Hruban et al., 1974) has been noted. These changes may cause severe restrictions in the normal function of liver cells.

Some progress has been made recently in analysing human liver fibrosis at the level of interstitial collagens using biochemical (Rojkind and MartinezPalomo, 1976; Seyer et al., 1977; Rojkind et al., 1979) and immunohistological methods (Ott et al., 1977; Wick et al., 1978). The data showed increased deposition of collagens type I and III in both periportal and intralobular areas. Rojkind et al. (1979) also reported on a distinct increase in collagenous $\mathrm{A}, \mathrm{B}$, and $\mathrm{E}$ chains, which are assumed to be derived from basement membranes (Chung et al., 1976). A precise anatomical localisation of such basement membrane components has yet not been achieved.

New approaches to identify individual basement membrane proteins by immunological techniques recently became feasible. A mouse tumour basement membrane (Orkin et al., 1977) was a convenient source to isolate collagen type IV and a large, noncollagenous glycoprotein, laminin (Timpl et al., 
1978, 1979a). Studies with antibodies prepared against both proteins showed that they are major constituents of authentic basement membranes in a variety of murine and human tissues. Alterations in basement membranes could be detected by immunofluorescence analysis in vascular proliferation associated with erythropoietic porphyria (Wick et al., 1979). Here, we used these antibodies and in addition antibodies to fibronectin (Stenman and Vaheri, 1978) for an immunohistological survey of basement membrane proteins in the liver from normal persons and in patients with alcoholic liver disease and chronic active hepatitis.

\section{Methods}

\section{CHARACTERISATION OF ANTIBODIES}

Rabbit and guinea-pig antisera were prepared against collagen type IV purified from an acetic acid extract of a mouse tumour (Timpl et al., 1978) and from a pepsin digest of human placenta (Glanville et al., 1979). Antibodies were purified from the antisera by immunoadsorption and failed as shown by radioimmunoassay to cross-react with interstitial collagens type I, II and III, type $\left(\mathrm{AB}_{2}\right)$ collagen from human placenta, and with laminin and fibronectin (Timpl $e t$ al., 1979b). Laminin, a large non-collagenous basement membrane protein, was also obtained from the mouse tumour matrix. Purified rabbit antibodies to laminin were those used in a recent study (Timpl et al., 1979a). Specific rabbit antibodies to human plasma fibronectin (cold-insoluble globulin) have been characterised previously (Dessau et al., 1978).

\section{INDIRECT IMMUNOFLUORESCENCE TEST}

The procedures were basically those described previously (Wick et al., 1975, 1978). Briefly, 4-6 $\mu \mathrm{m}$ thick unfixed frozen liver sections were air-dried for 20 minutes and then exposed to rabbit antibodies to collagen type IV $(30 \mu \mathrm{g} / \mathrm{ml})$, to laminin $(25 \mu \mathrm{g} / \mathrm{ml})$ or to fibronectin $(25 \mu \mathrm{g} / \mathrm{ml})$. Positive staining was still observed when these antibodies were used at a concentration of $1-5 \mu \mathrm{g} / \mathrm{ml}$. Normal rabbit IgG $(100 \mu \mathrm{g} / \mathrm{ml})$ or phosphate-buffered saline $\mathrm{pH} 7 \cdot 2$ served as controls and showed no reactions on all specimens. Antibody-treated slides were then visualised with FITC-conjugated or TRITC-conjugated goat anti-rabbit immunoglobin and FITC-conjugated anti-guinea-pig immunoglobulin (Behringwerke AG, Marburg, Germany, or Dakopatts SA, Denmark) used at optimal dilution as determined by chessboard titration. Readings were performed with a Zeiss Standard 18 microscope (filter combination BP 455, BP 490, FT 510, LP 520) or with a Leitz Ortholux microscope appropriately equipped for the two wavelength method (FITC filter combination BP 450/490, RKP 510, LP 515; TRITC filter combination BP 530/560, RKP 580, LP 580) both operating with indirect illumination. Photographs were taken on Agfa 50s Professional colour slide films.

\section{ORIGIN AND TREATMENT OF LIVER}

SPECIMENS

Liver tissue was obtained from persons without any history of liver disease (normal controls) and from patients with alcoholic liver disease or chronic active hepatitis (Table). The normal liver controls were obtained at necropsy from patients dying after cerebral injury (two) or after myocardial infarction (one). All these patients had a normal liver histology, except for the latter (71 years old) case which showed some enlargement of the periportal fields, and were negative for hepatitis B antigen and antibody. Diagnosis of liver patients was based on complete histological, immunological, and laboratory evaluation. Alcohol consumption in the patients with alcoholic fatty liver and alcoholic hepatitis was $120-300 \mathrm{~g} /$ day over a period of six to 25 years. Associated diseases were pancreatitis (three), Mallory-Weiss syndrome (one), peripheral neuropathy (one), and perforated ulcer of the stomach

Table Origin and classification of liver specimens used for immunofluorescence analysis

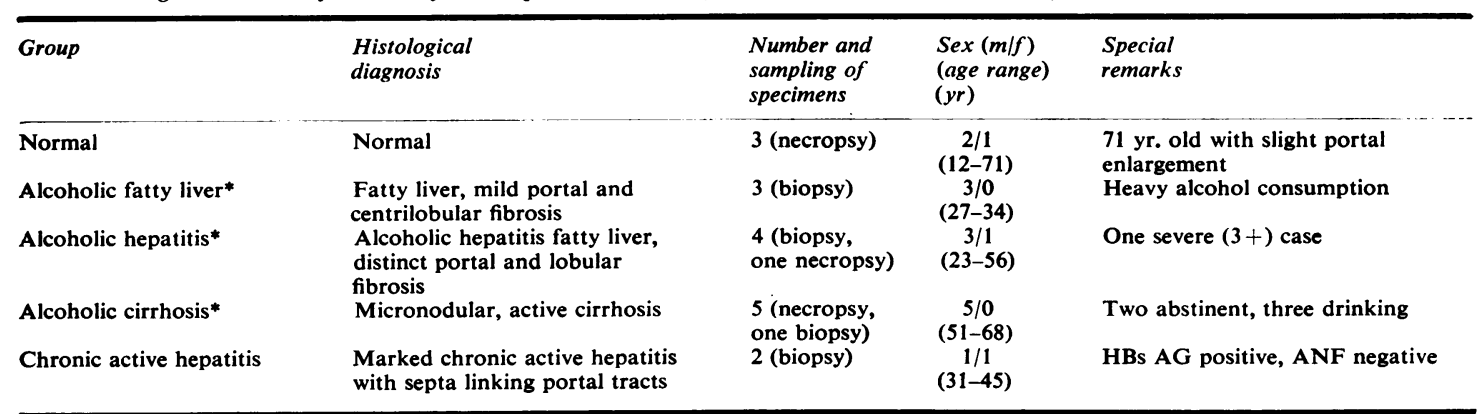

*Characterisation and grading as described by Lischner et al. (1971). 
(one). Cause of death in the patients with alcoholic cirrhosis was hepatic coma (two), oesophageal bleeding (one), and pneumonia (one). All patients with alcoholic liver disease were negative for $\mathbf{H B}_{\mathrm{s}}$, antigen and antibody. Both patients with chronic active hepatitis had a history of hepatitis $B$ but not of drug or alcohol abuse. One was on treatment with fluorocortolone $(10 \mathrm{mg} / \mathrm{d})$ and penicillamine $(100$ $\mathrm{mg} / \mathrm{d}$ ).

Biopsies were taken six hours to seven days after admission to the hospital by percutaneous needle biopsy or in one case by surgical wedge biopsy. Necropsy material was obtained between five to 12 hours after death and showed no signs of gross autolytic changes. Part of the material (minimal size $15 \times 1.6 \mathrm{~mm}$ ) was processed for routine histology. An equal portion was frozen within 10-15 minutes in liquid nitrogen and stored at $-85^{\circ} \mathrm{C}$ until used for immunofluorescence.

\section{Results}

IMMUNOFLUORESCENCE ANALYSIS OF

COLLAGEN TYPE IV, LAMININ, AND

FIBRONECTIN IN NORMAL LIVER

Portal tract

Antibodies to collagen type IV, laminin, and fibronectin showed brilliant staining of basement membranes beneath the endothelial lining of hepatic arteries, of portal veins and lymphatic vessels, around smooth muscle cells in the vessel walls and around bile ducts and ductules and nerve axons (Fig. 1a-c, g). The reaction was specific, as exposure to non-immune rabbit IgG produced no staining in addition to some yellow autofluorescence of pigment particles in the parenchyma (Fig. 1d). Usually, the strongest staining was observed with anti-laminin antibodies, while antibodies to fibronectin showed no or only weak reaction with bile ducts and lymphatic vessels. The interstitial matrix of the portal region showed usually no reaction with any of these antibodies. The intensity of staining was increased at the border between periportal tract and limiting liver cell plates (Fig. le, f), which is distinctly demarcated by small lymphatic vessels and involved mainly lymphatic basement membranes, but occasionally matrix material.

\section{Parenchyma}

Collagen type IV and fibronectin were deposited along the sinusoids between endothelial lining and liver cell plates all over the acinar tissue (Fig. 1a, c). The staining was moderate and did not always appear laminar but rather as a band-like or speckled pattern. No reaction of the sinusoidal lining was observed with antibodies to laminin (Fig. 1b, f). The wall of the central vein showed a ring-like deposit of collagen type IV and fibronectin but not of laminin. Th's pattern appeared to be continuous with the sinusoidal lining. Hepatic cells were uniformly negative with all three antibodies. In a few sections Kupffer cells and Ito cells could be visualised but showed no cytoplasmic staining.

CHANGES OI STAINING PATTERN IN FIBROTIC LIVERS

Fatty liver

Examination of liver sections from two patients showed only ;mall differences when compared with the normal pattern. The sinusoidal framework of collagen type IV and fibronectin appeared to be discontinuous in a few places. Occasionally, increased staining was observed around the wall of the terminal vein indicating discrete central fibrosis which may have escaped detection by conventional histological staining. The react on with antibodies to laminin remained negative in the sinusoids. Another, more severe case (alcohol consumption $300 \mathrm{~g} / \mathrm{d}$ for 12 years) showed an increased intensity of intralobular staining for collagen type IV and fibronectin and, in addition, now a distinct perisinusoidal reaction for laminin (Fig. 2a-c).

\section{Alcoholic hepatitis}

Sections were examined from four patients varying in histological grading from mild to severe (Lischner et al., 1971). The intensity of intralobular staining for collagen type IV fibronectin and laminin was increased and resembled those shown in Fig. 2a-c. The matrix of portal fields stained strongly for collagen type IV and fibronectin, the intensity approximately following the histological grading. Where septa are formed, the most intense staining was observed in the border regions involving vessels, lymphatics, and bile ducts but also matrix deposits. Similar changes are observed in cirrhosis (see below, Fig. $2 \mathrm{f}-\mathrm{g}$ ).

\section{Alcoholic cirrhosis}

All the antibodies reacted strongly with basement membranes located in enlarged portal fields and fibrotic septa. Deposits of fibronectin and of collagen type IV forming a dense layer of spot-like and fibrillar structures could also be detected in the interstital matrix (Figs. 2d, 3a), while staining for laminin was negative (Figs. 2c, 3b). An accentuated staining was found for all three proteins in the septal border, including blood and lymph vessels, bile ductules, and matrix material (Fig. 2f-h). Very marked deposits of laminin were seen in the adjacent parenchyma, sometimes encircling liver cell islands or single cells. Similar, discontinuous projections into the parenchyme are also observed after staining 

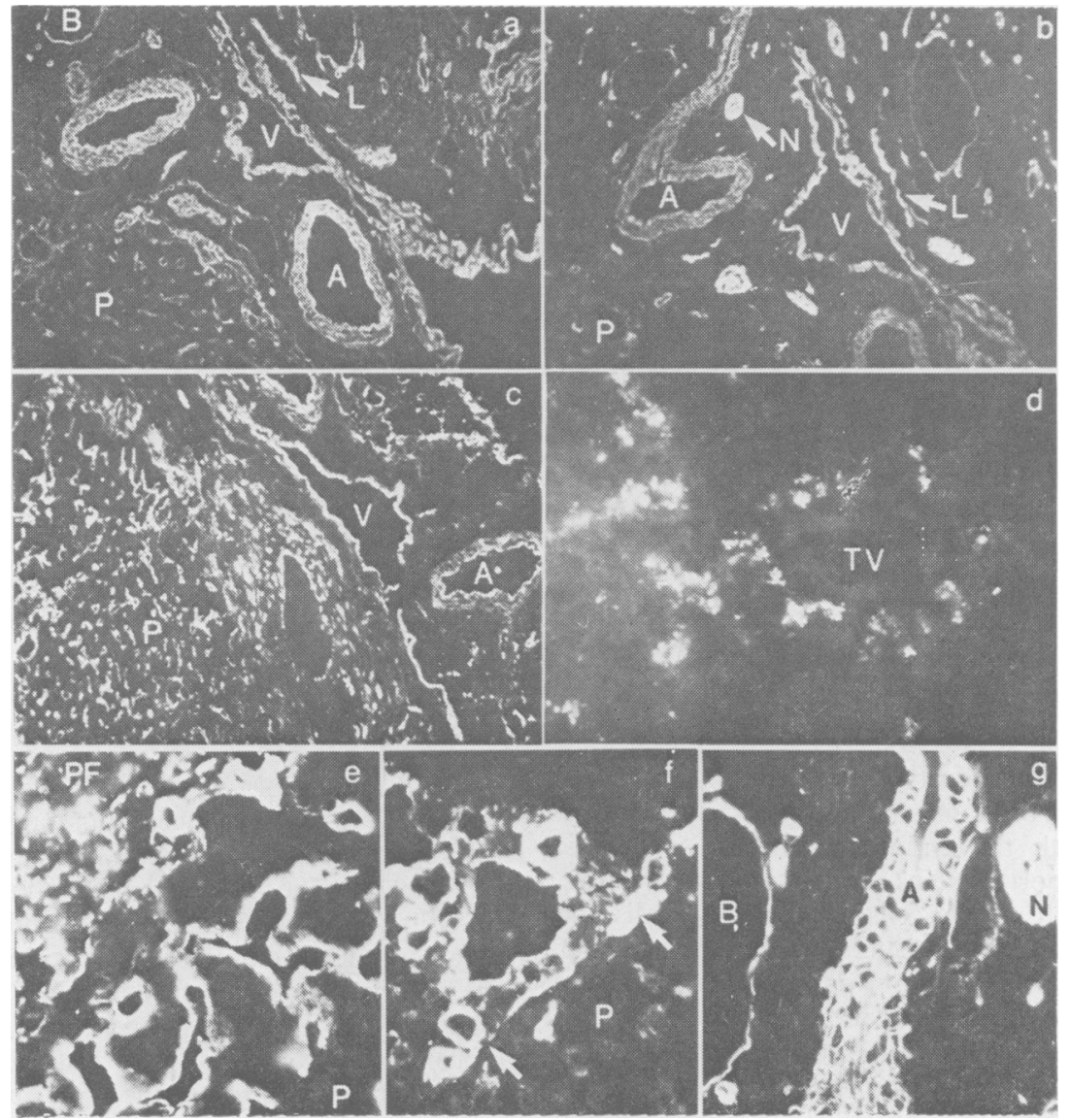

Fig. 1 Immunofluorescence staining on sections of a normal human liver with rabbit antibodies against type IV collagen $(a, e)$, laminin $(b, f, g)$, and fibronectin $(c)$. For a negative control section $d$ was exposed to non-immune rabbit IgG. a-d are semiserial sections (magnification $\times 40$ ) showing a large portal tract with hepatic artery $(A)$ portal veins $(V)$, bile ducts $(B)$, lymphatic vessels $(L)$ and nerves $(N)$ as well as an adjacent section of parenchyma $(P) . e, f$ show the border (arrows) between a portal field $(P F)$ and adjacent parenchyma $(P)$ at higher magnification $(\times 160)$. Note that antibodies to type IV collagen $(a, e)$ stain in the portal field basement membranes of arteries, veins, lymphatic vessels, bile ducts, and nerve axons and in the parenchyma the sinusoidal lining. No or only very weak reaction was observed with the interstitial matrix. Antibodies to fibronectin (c) show an almost identical staining pattern. Antibodies to laminin $(b, f)$ show a particularly brilliant staining of all basement membranes in the portal field (see also section $g$ ) (magnification $\times 160$ ), but failed to react with the sinusoidal lining in the parenchyma $(f)$. The control section $(d)$ was photographed after double exposure time and shows a terminal vein (TV) and surrounding parenchyma. Note the autofluorescence of intracellular pigments in the parenchyma. 


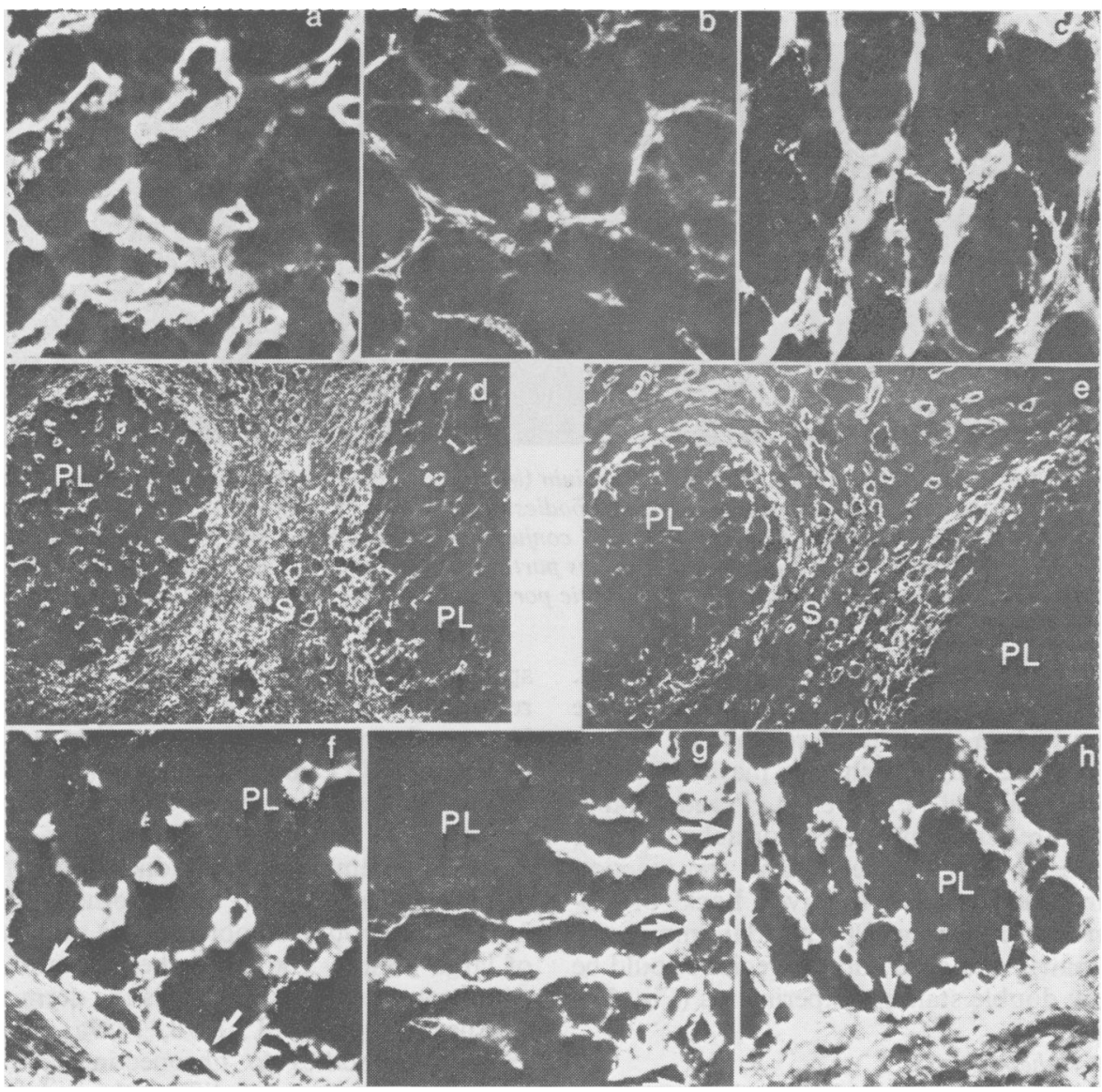

Fig. 2 Immunofluorescence staining of basement membrane proteins on liver sections of a patient with alcoholic fatty liver $(a-c)$ and of a patient with alcoholic cirrhosis $(d-h)$. Staining was with antibodies to type IV collagen $(a, d, f)$, to laminin $(b, e, g)$ or to fibronectin $(c, h)$. Sections a-c (magnification $\times 160)$ show a portion of the parenchyma with intense staining of the perisinusoidal lining by all three antibodies. The semiserial sections $d$ and $e$ (magnification $\times 40)$ show pseudolobules $(P L)$ surrounded by septa $(S)$ in a fibrotic area. Note the strong staining for type IV collagen in basement membranes and interstitial matrix of the septum and the sinusoidal lining in the pseudolobuli. Laminin appeared restricted to the septal basement membranes and to sinusoidal regions located close to the septum. Staining intensity with all antibodies was markedly increased along the border (arrows) between septum and pseudolobulus as shown in sections $f-g$ (magnification $\times 160$ ). Conventional histology (not shown): the 30 year old patient with alcoholic fatty liver showed marked steatosis involving $75 \%$ of hepatocytes, slight portal and centrilobular fibrosis but no signs of alcoholic hepatitis. The 62 year old patient with alcoholic cirrhosis died of hepatic coma. His liver was obtained at necropsy and showed septa with lymph cell infiltration and proliferation of bile ductules. Liver cell islands, moderate necrosis with inflammatory reaction and proliferation of capillaries and lymphatic vessels were prominent at the septal-parenchymal borders. 


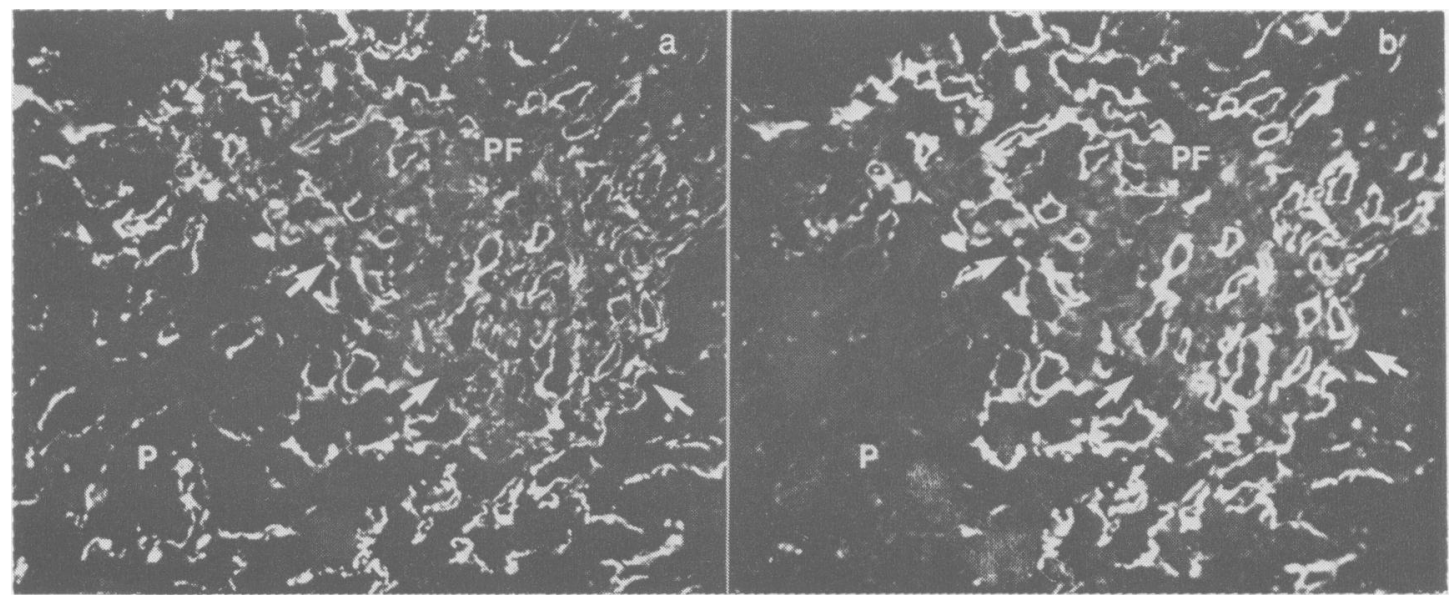

Fig. 3 Double staining for type IV collagen (a) and laminin (b) on a liver section from a patient with alcoholic cirrhosis. The section was first exposed to guinea-pig antibodies against type IV collagen and then to rabbit antibodies against laminin which were visualised by specific anti-IgG conjugates containing the FITC or TRITC label, respectively. Note the lack of a complete codistribution of both proteins particularly in the sinusoids of the central region of parenchyma $(P)$ and in the interstitial matrix of the fibrotic portal field $(P F)$. Arrows denote the portal-parenchymal border. $\times 60$.

with antibodies to collagen type IV and fibronectin. This excessive deposition of basement membrane proteins resulted in a portal-parenchymal border which was considerably less sharply marked than in normal liver tissue (cf. Fig. 1e, f). Pseudolobules show in the more central portion a normal pattern of collagen type IV and fibronectin and the reaction for laminin was usually negative. Lack of codistribution of collagen type IV and laminin in the interstitial matrix and centrilobular regions could be confirmed by double staining experiments (Fig. 3).

\section{Chronic active hepatitis}

In both patients studied the changes in deposition and intensity of collagen type IV and fibronectin in enlarged portal fields and in the parenchyma resembled those observed in severe alcoholic liver disease. The reaction for laminin was generally negative within the sinusoids, however, but frequently deposits were observed projecting with multiple stretches into the parenchyma adjacent to portal and septal margins.

\section{Discussion}

The present study was aimed at the identification of structures related to basement membranes in human liver by using well-characterised antibodies against collagen type IV (Timpl et al., 1978; 1979b), against a non-collagenous basement membrane protein which we have named laminin (Timpl et al., 1979a) and against plasma fibronectin (Dessau et al., 1978; Stenman and Vaheri, 1978). The antibodies were specific for each antigen and also failed to crossreact with interstitial collagens and procollagens. Immunofluorescence analysis with antibodies to collagen type IV and laminin showed in a variety of human tissues staining restricted to basement membranes-for example, of glomerular and tubular basement membranes in kidney and of basement membranes underneath the endothelial lining in the intima and around smooth muscle cells in the media of large vessels. The antibodies did not stain interstitial connective tissue such as the dermis or tendon bundles (Timpl et al., 1978, 1979a; Rohde et al., 1979b. Antibodies to fibronectin have been previously found to react differently and stained only certain basement membranes as well as material in loose interstitial connective tissue (Stenman and Vaheri, 1978).

In sections of normal human liver the three different antibodies reacted with a few exceptions in a similar manner and with comparable intensity with blood vessel walls, lymphatic vessels, bile ducts and ductules, and with the membrane around nerve axons. This pattern is not unexpected, as basement membranes have been demonstrated in these structures by electron microscopy (Vracko, 1974). Little or no staining was observed in the interstitial connective tissue of portal tracts, not even with antibodies to fibronectin. In the parenchyma distinct reaction along the perisinusoidal lining was found for collagen type IV and fibronectin but not for laminin.

The staining for collagen type IV suggests that basement membrane-like structures surround the 
perisinusoidal surface in normal liver, although typical continuous basement membranes could not be detected by electron microscopy (Schaffner and Popper, 1963; Phillips and Steiner, 1966; Vracko, 1974). In other basement membranes collagen type IV and laminin show extensive codistribution and react in immunofluorescence tests with equal intensity (Rohde et al., 1979b). The lack of staining in the sinusoidal lining by antibodies to laminin may be due to masking or a decrease in the amount of antigen. The data indicate that the architecture of this basement membrane is different, which perhaps for this reason represents a less selective permeability barrier than other basement membranes, thus allowing a rapid metabolic exchange between hepatocytes and the circulation (Schaffner and Popper, 1963). Whether fibronectin is associated with the perisinusoidal basement membrane or with underlying collagen fibrils (Schaffner and Popper, 1963) remains to be determined by better resolving techniques such as immunoelectronmicroscopy. Collagens and procollagens type I and III have been demonstrated in the perisinusoidal space by immunofluorescence studies (Gay et al., 1975; Ott et al., 1977; Wick et al., 1978) and codistribution of these collagens with fibronectin was found in cell culture studies (Vaheri et al., 1978).

We have also examined a limited number of liver sections from patients showing varying degrees of fibrosis and found a few remarkable differences from the normal staining patterns. The intensity of the reaction for collagen type IV and fibronectin was increased in the perisinusoidal sites, which suggested increased production of these proteins. Antibodies to laminin showed now distinct perisinusoidal staining, which was particularly strong in the border regions between liver nodules and fibrotic septa. These changes may precede or correlate with the capillarisation of liver sinusoids found in active and late stages of cirrhosis that are characterised by an electronmicroscopically continuous basement membrane of $100 \AA$ thickness underneath the lining cells (Schaffner and Popper, 1963; Phillips and Steiner, 1966). The strong increase in fibronectin staining in the portal matrix and in fibrotic septa resembles other observations of active fibronectin production in proliferating connective tissue (Linder et al., 1978). An equally intense reaction for collagen type IV in the interstitial matrix is a surprising finding if fibroblasts are exclusively involved in producing the matrix proteins. Usually, fibroblasts do not synthesise basement membrane proteins but may have changed their phenotype under pathological conditions.

Our data agree basically with the findings of an increase in collagenous $\mathrm{A}, \mathrm{B}$, and $\mathrm{E}$ chains in human liver fibrosis (Rojkind et al., 1979). A preliminary immunofluorescence analysis with antisera against this mixture of antigens showed apparently a persinusoidal pattern (Biempica et al., 1977) similar to that described in the present study. Current evidence indicates that these collagenous polypeptides are, however, not related to collagen type IV (Chung et al., 1976; Timpl et al., 1979b,c) which was originally identified as the major collagenous component of basement membranes (Kefalides, 1973). A full description of the major constituents of basement membranes is still not available and future developments (Timpl et al., 1979c) will provide more refined tools for analysing basement membrane co.lagens in normal and fibrotic livers.

Vracko (1974) has discussed the concept that basement membranes provide a scaffold for normal tissue structure and direct intact repair of lesions. Disorganised production of basement membranes may occur in liver fibrosis and distort the normal relationship between liver cell plates and surrounding connective tissue. The immunofluorescence data showing that basement membrane proteins undergo certain changes in deposition when a normal liver becomes fibrotic are compatible with this concept. However, immunohistological as well as electronmicroscopical localisation of basement membranes, even though complementing each other, are both qualitative approaches and are certainly not sufficient to understand the dynamics of these processes. Based on previous immunofluorescence data which suggest increased procollagen type III synthesis in liver fibrosis (Wick et al., 1978), we have developed a specific radioimmunoassay which demonstrated enhanced serum levels of this antigen in patients with acute and chronic hepatitis and with alcoholic liver disease (Rohde et al., 1979a). Similar assays are feasible for basement membrane components (Timpl et al., 1979a,b,c) and may provide another means for analysing basement membrane formation in liver fibrosis.

\section{Note added at proof stage}

A recent study of Rudolph et al. (1979) demonstrated a large number of myofibroblasts in fibrotic septa of cirrhotic livers. These cells are involved in scar contraction and located close to structures having the appearance of basement membranes. It is possible that our observation on abundant amounts of type IV collagen in fibrotic septa is correlated with the presence of such myofibroblasts.

Histological evaluation of liver sections was performed by $\mathrm{Dr} \mathrm{H}$. Kalbfleisch, Institute of Pathology, Marburg. We acknowledge the technical assistance 
of Mrs U. Krauskopf and Mrs A. Schalk. The study was supported by grants of the Deutsche Forschungsgemeinschaft (projects $\mathrm{Ha}$ 956/4 and Ti 95/4) and by NIH contract No. NO1-DE-82412.

\section{References}

Biempica, L., Morecki, R., Wu, C. H., Giambrone, M. A., and Rojkind, M. (1977). Isolation and immunohistochemical localization of a component of basement membrane collagen in human liver (abstract). Gastroenterology, 73, 1213.

Bucher, N. L. R. (1963). Regeneration of mammalian liver. International Review of Cytology, 15, 245-300.

Cossel, L. (1966). Über akutes Auftreten von Basalmembranen an den Lebersinusoiden. Beiträge zur Pathologie, 134, 103-122.

Chung, E., Rhodes, R. K., and Miller, E. J. (1976). Isolation of three collageneous components of probable basement membrane origin from several tissues. Biochemical and Biophysical Research Communications, 71, 1167-1174.

Dessau, W., Sasse, J., Timpl, R., Jilek, F., and von der Mark, K. (1978). Synthesis and extracellular deposition of fibronectin in chondrocyte cultures. Journal of Cell Biology, 79, 342-355.

Gay, S., Fietzek, P. P., Remberger, K., Eder, M., and Kühn, K. (1975). Liver cirrhosis: immunofluorescence and biochemical studies demonstrate two types of collagen. Klinische Wochenschrift, 53, 205-208.

Glanville, R. W., Rauter, A., and Fietzek, P. P. (1979). Isolation and characterisation of a native placental basement-membrane collagen and its component $\alpha$ chains. European Journal of Biochemistry, 95, 383-389.

Hruban, Z., Russel, R. M., Boyer, J. L., Glagov, S., and Bagheri, S. A. (1974). Ultrastructural changes in livers of two patients with hypervitaminosis A. American Journal of Pathology, 76, 451-461.

Kefalides, N. A. (1973). Structure and biosynthesis of basement membranes. International Review of Connective Tissue Research, 6, 63-104.

Linder, E., Stenman, S., Lehto, V. P., and Vaheri, A. (1978). Distribution of fibronectin in human tissues and relationship to other connective tissue components. Annals of the New York Academy of Sciences, 312, 151-159.

Lischner, M. W., Alexander, J. F., and Galambos, J. T. (1971). Natural history of alcoholic hepatitis. I. The acute disease. American Journal of Digestive Diseases, 16, 481-494.

Orkin, R. W., Gehron, P., McGoodwin, E. B., Martin, G. R., Valentine, T., and Swarm, R. (1977). A murine tumour producing a matrix of basement membrane. Journal of Experimental Medicine, 145, 204-220.

Ott, U., Hahn, E., Moshudis, E., Bode, J. C., and Martini, G. A. (1977). Immunhistologischer Nachweis von Typ I- und Typ III-Kollagen in Leberbiopsien: Frühe und späte Veränderungen bei alkoholischer Lebererkrankung. Verhandlungen der Deutschen Gesellschaft für innere Medizin, 83, 537-540.
Phillips, M. J., and Steiner, J. W. (1966). Electron microscopy of cirrhotic nodule. Tubularization of the parenchyma by biliary hepatocytes. Laboratory Investigation, 15, 802-817.

Rohde, H., Vargas, L., Hahn, E., Kalbfleisch, H., Bruguera, M., and Timpl, R. (1979a). Radioimmunoassay for type III procollagen peptide and its application to human liver disease. European Journal of Clinical Investigation, 9 (in press).

Rohde, H., Wick, G., and Timpl, R. (1979b). Immunochemical characterisation of the basement membrane glycoprotein laminin. European Journal of Biochemistry (in press).

Rojkind, M., Giambrone, M.-A., and Biempica, L. (1979). Collagen types in normal and cirrhotic liver. Gastroenterology, 76, 710-719.

Rojkind, M., and Martinez-Palomo, A. (1976). Increase in type I and type III collagens in human alcoholic liver cirrhosis. Proceedings of the National Academy of Sciences of the USA, 73, 539-543.

Rudolph, R., McClure, W. J., and Woodward, M. (1979). Contractile fibroblasts in chronic alcoholic cirrhosis. Gastroenterology, 76, 704-709.

Schaffner, F., and Popper, H. (1963). Capillarization of hepatic sinusoids in man. Gastroenterology, 44, 239-242.

Seyer, J. M., Hutcheson, E. T., and Kang, A. H. (1977). Collagen polymorphism in normal and cirrhotic human liver. Journal of Clinical Investigation, 59, 241-248.

Stenman, S., and Vaheri, A. (1978). Distribution of a major connective tissue protein, fibronectin, in normal human tissues. Journal of Experimental Medicine, 147, 1054-1064.

Timpl, R., Glanville, R. W., Wick, G., and Martin, G. R. (1979b). Immunochemical study on basement membrane (type IV) collagens. Immunology, 38, 109-116.

Timpl, R., Martin, G. R., Bruckner, P., Wick, G., and Wiedemann, H. (1978). Nature of the collagenous protein in a tumor basement membrane. European Journal of Biochemistry, 84, 43-52.

Timpl, R., Risteli, J., and Bächinger, H. P. (1979c). Identification of a new basement membrane collagen by the aid of a large fragment resistant to bacterial collagenase. FEBS Letters, 101, 265-268.

Timpl, R., Rohde, H., Gehron-Robey, P., Rennard, S. R., Foidart, J. M., and Martin, G. R. (1979a). Laminin, a glycoprotein from basement membranes. Journal of Biological Chemistry, 254, 9933-9937.

Vaheri, A., Kurkinen, M., Lehto, V. P., Linder, E., and Timpl, R. (1978). Codistribution of pericellular matrix proteins in cultured fibroblasts and loss in transformation: fibronectin and procollagen. Proceedings of the National Academy of Sciences USA, 75, 4944-4948.

Vracko, R. (1974). Basal lamina scaffold-anatomy and significance for maintenance of orderly tissue structure. American Journal of Pathology, 77, 314-338.

Wick, G., Brunner, H., Penner, E., and Timpl, R. (1978). The diagnostic application of specific antiprocollagen sera. II. Analysis of liver biopsies. International Archives of Allergy and Applied Immunology, 56, 316-324. 
Wick, G., Furthmayr, H., and Timpl, R. (1975). Purified antibodies to collagen: an immunofluorescence study of their reaction with tissue collagen. International Archives of Allergy and Applied Immunology, 48, 664-679.
Wick, G., Hönigsmann, H., and Timpl, R. (1979). Immunofluorescence demonstration of type IV collagen and a non-collageneous glycoprotein in the thickened vascular basal membranes in protoporphyria. Journal of Investigative Dermatology. (In press). 